\title{
Neuro-protective Effect of Ayurveda Formulation, Saraswatharishtam, on Scopolamine Induced Memory Impairment in Animal Model
}

\author{
Jai Prabhu', K Prabhu², Anathbandhu Chaudhuri ${ }^{3}$, Mudiganti Ram Krishna Rao ${ }^{4, *}$, VS Kalai Selvi ${ }^{5}$, TK Balaji , \\ Sruthi Dinakar ${ }^{7}$
}

Jai Prabhu', K Prabhu²,

Anathbandhu Chaudhuri ${ }^{3}$, Mudiganti Ram Krishna Rao ${ }^{4, *}$, VS Kalai Selvi ${ }^{5}$, TK Balaji ${ }^{6}$, Sruthi Dinakar $^{7}$

${ }^{1}$ Research Scholar, Sree Balaji Medical College and Hospital, Chennai, INDIA ${ }^{2}$ Associate Professor, Department of Anatomy, Sree Balaji Medical College and Hospital, Chennai, INDIA.

${ }^{3}$ Assistant Professor, Department of

Biological Sciences, University of Alabama,

Tuscaloosa, Alabama, 35401, USA.

${ }^{4}$ Professor, Department of Industria

Biotechnology, Bharath Institute of Higher Education and Research, Chennai, INDIA.

${ }^{5}$ Professor, Department of Biochemistry, Sree

Balaji Medical College and Hospital, Chennai,

INDIA.

${ }^{6}$ Professor, Department of Anatomy,

Chettinad Health City, Chennai 603103,

INDIA.

${ }^{7}$ Ayurvedic Physician, Kottakkal Arya Vaidhya Sala, Chennai, INDIA.

\section{Correspondence}

\section{Mudiganti Ram Krishna Rao}

Professor, Department of Industrial

Biotechnology, Bharath Institute of Higher

Education and Research, Chennai, INDIA.

E-mail: mrkrao1455@gmail.com

History

- Submission Date: 22-08-2019.

- Review completed: 04-10-2019;

- Accepted Date: 07-10-2019.

DOI : 10.5530/pj.2020.12.2

Article Available online

http://www.phcogj.com/v12/i1

Copyright

(C) 2020 Phcogj.Com. This is an openaccess article distributed under the terms of the Creative Commons Attribution 4.0 International license.

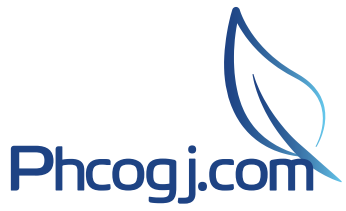

\begin{abstract}
Introduction: In the management of neurodegenerative and neuropsychiatric diseases, memory loss remains very challenging. Saraswatharishtam (SWRT) is an ayurvedic formulation prescribed for several neurological illnesses like acute anxiety, partial memory loss, slurred speech, neuro degenerative diseases like Parkinson's, Alzheimer's etc. Methods: Present study explores the possibilities of curative effects of SWRT on Scopolamine induced memory impairment and to compare the effects of commonly used drug piracetam. Adult Wistar Swiss albino mice were used for this experiment and divided into five different groups for the treatments of the drugs in various combinations. The first group was vehicle treated control while the second group was treated with scopolamine to induce memory impairment. The third group of animals were treated with Scopolamine where the mice were pretreated with standard neuroprotective drug Piracetam, while the fourth and fifth group of animals were treated with scopolamine and the animals were pretreated with SWRT at the doses of 200 and $400 \mathrm{mg} / \mathrm{kg}$ respectively to compare with the effect of Piracetam. Scopolamine was administered on day eight, only for 45 minutes in all the cases (Group I- Group V). Several neurobehavioral parameters were examined to confirm the neuroprotective effects of SWRT. Results: Saraswatharishtam significantly reversed the memory loss in mice model revealed from elevated plus maze, radial maze and rectangular maze experiments justifying its neuroprotective potential as observed in usually used synthetic Piracetam. SWRT was found to be nontoxic and very promising antioxidant recorded from acute and chronic toxicological studies. Conclusions: It is suggested that SWRT, could be used as safe and easily available Ayurveda medicine to treat neurological dysfunctions without any side effects. Further translational research is needed to explore its neuro-protective potential.

Key words: Saraswatharishtam, Ayurvedic medicine, Scopolamine, Piracetam, Elevated Plus Maze, Antioxidant, Neuroprotection.
\end{abstract}

\section{INTRODUCTION}

Memory loss is a common phenomenon and remains a challenge in management of several neurological diseases like epilepsy, Alzheimer's, neuro-degenerative, neuro-metabolic, vascular disorders of central nervous system and in psychosomatic disorders. People suffer from several age related physiological disorders including learning and memory loss. The incidence, prevalence, morbidity, mortality and burden of disease have become increasingly relevant to the practice of clinical public health and health policy. ${ }^{1,2}$ SWRT is an Ayurvedic formulation prescribed for acute anxiety, fatigue, insomnia, partial loss of memory and low grasping power. ${ }^{3}$ This herbal brain tonic is also prescribed for slurred speech, dementia, certain neuro degenerative diseases and several other physiological disorders. In consonance with previous studies, in which Saraswatha choorna (the powder form of Saraswatharishtam) was reported to have antidepressant and anti-anxiety roles, the present study was conducted. Some reports on the anti-amnesic roles of plant derived medicines as compared to piracetam on scopolamine induced memory loss in animal models are available. ${ }^{4}$ Scopolamine is a centrally acting muscarinic cholinergic antagonist used in animal experiments to induce memory impairment. ${ }^{5,6}$ Scopolamine is commonly used as model for characterization of potential cognition enhancing drugs. Recently several studies reported that Scopolamine induced memory impairment in animal model is closely associated with the brain..$^{7-10}$ Piracetam comes under smart drugs used for neuro-protection on experimental animals since last three decades. ${ }^{11,12}$ This drug plays a critical role in enhancing acetylcholine function through muscarinic cholinergic receptors and these receptors play a vital role in memory and learning. Piracetam enhances cell membrane permeability and increase oxygen consumption.

The present study deals with comparing the positive effects of SWRT with the standard drug Piracetem in Scopolamine induced memory impairment on animal model. Standardization and evaluation of scientific efficacy of contemporary and alternative medicines is the need of the hour due to various

Cite this article: Prabhu J, Prabhu K, Chaudhuri A, Rao MRK, Selvi VSK, BalajiTK, et al. Neuroprotective Effect of Ayurveda Formulation, Saraswatharishtam, on Scopolamine Induced Memory Impairment in Animal Model. Pharmacog J. 2020;12(1):06-13. 
side effects of modern synthetic medicines. ${ }^{13-15}$ This study encompasses three major areas comprising of toxicity tests of SWRT alone, effects of SWRT on Elevated Plus maze to find out the recovery of memory loss and antioxidant properties of SWRT in scopolamine induced memory impaired mouse model. This knowledge can put forth the efficacy and validity of such affordable alternative form of plant medicine.

\section{MATERIALS AND METHODS}

\section{Experimental design}

This experiment has conducted on an animal model to study the neuroprotective role of SWRT on scopolamine induced memory impairment and compare the effect with commonly used drug Piracetam.

\section{Ethical clearance}

This study was approved by IAEC (Institution of Animal Ethical Committee) of KMCH (Kovai Medical Center and Hospital) governed by CPCSEA (Committee for the Purpose of Control and Supervision of Experiments on Animals), Government of India. Proposal number: 685/po/02/a/CPCSEA/ DATED 2015/2016.

\section{Ayurvedic medicine and other drugs}

\section{Saraswatharishtam (SWRT)}

Procured from standard Ayurveda vendor at Chennai, India. SWRT consists of the following plant ingredients: 1. Bacopa moniera, 2. Zingiber offininale, 3. Anethum sowa, 4. Operculina ipomoea, 5. Piper longum, 6. Syzygium aromaticum, 7. Acorus calamus, 8. Saussurea lappa, 9. Withania somnifera, 10. Terminalia chebula, 11. Tinospora cordifolia, 12. Elettaria cardmomum, 13. Terminalia embelica, 14. Cinamomum zeylanicum, 15. Asparagus racemosus, 16. Pueraria tuberose, 17. Terminalia belerica and 18. Pure Metallic gold.

\section{Scopolamine}

It is a prescription drug usually used to treat Parkinson's disease and several other symptoms like, nausea, vomiting, caused by motion sickness. However, it causes memory loss with overdose. Scopolamine was purchased Alchem Int Pvt Ltd Company, India.

\section{Piracetam}

Generally used as memory and cognitive enhancer, Alzheimer's disease, dementia, and several other neurological dysfunctions. Piracetam was purchased from Aliud Pharma gmbH Company.

\section{Treatment plan}

The experiment was divided in to five different groups. In group I, the animals received normal saline for eight consecutive days and served as vehicle control (not treated with any drugs). Group III served as standard and received $200 \mathrm{mg} / \mathrm{kg}$ of piracetam (memory enhancer) for eight consecutive days. Group IV and Group V served as test animals and received $200 \mathrm{mg} / \mathrm{kg}$ and $400 \mathrm{mg} / \mathrm{kg}$ of SWRT respectively for eight consecutive days. On $8^{\text {th }}$ day, after 90 minutes of all the drug administration, animals from group II, group III, group IV \& group V, were treated with $0.4 \mathrm{mg} / \mathrm{kg}$ of Scopolamine once. All the behavioral data were collected within 45 minutes till 24 hours depending on the different parameters studied. Each Group consisted of six animals.

\section{Animals}

Healthy adult Swiss Albino mice of both sexes, weight ranges from 25-30 gram of body weight were used as experimental animals following the OECD (Organization for Economic Co-operation and Development) 423 guidelines. Standard laboratory animal food pellets with water (ad libitum) was given to maintain the health of the mice. Photoperiod was maintained as $12 \mathrm{~L}: 12 \mathrm{D}$ with a room temperature at $22^{\circ} \mathrm{C} \pm 3^{\circ} \mathrm{C}$ and humidity at $45-55 \%$ where mice were housed.

\section{Study parameters}

The study was divided into three major components:

\section{Toxicology studies}

To find out the toxic effects of SWRT the animals were treated with three different doses of SWRT (50, 1000 and $2000 \mathrm{mg} / \mathrm{Kg}$ body weight) and tested the acute and chronic toxicity.

\section{Behavioral parameter analysis}

To find out the neuro-protective effects of SWRT on scopolamine induced memory impairment using mouse model.

i. Locomotor Activity tested using actophotometer

ii. Muscle coordination activity using rotarod

iii. Elevated Plus Maze (Hebb Williams Maze - Rectangular Maze) and Radial Arm Maze use to test the transfer latency and memory errors.

\section{In vivo antioxidant studies}

In vivo antioxidant activities of Catalase (Cat), Super Oxide dismutase SOD) and Reduced Glutathione (GSH) were conducted to understand the role of SWRT on these levels of these three enzymes.

\section{METHODOLOGY}

\section{Toxicology studies \\ Acute toxicity studies}

Acute oral toxicity refers to adverse effects occurring followed by the oral administration of different doses of SWRT given within 24 hours. Followed by a 2 hours period of fasting, animals were weighed and SWRT was administered orally by dissolving it in water through gavage using specially designed mouse oral needle at the doses of 50, 1000 and 2000 $\mathrm{mg} / \mathrm{kg}$ body weight. Food was withheld for 2 hours after administration of SWRT, only supplemented with water. The mice were monitored for the first 30 minutes and periodically every 24 hours. Special attention was given for the first 1-4 hours after drug administration. Seventeen different types of behavioural parameters such as alertness, grooming, touch response, torch response, pain response, tremor, convulsion, urination, salivation etc., (Supplementary Table 1) were judged to test the acute toxicity symptoms after SWRT administration.

\section{Chronic toxicity studies}

Chronic oral toxicity refers to adverse effects occurring followed by the oral administration of different doses of SWRT (50, 1000 and $2000 \mathrm{mg} /$ $\mathrm{kg}$ ). The mice were followed up for a period of 14 days to check for chronic toxicity. Chronic toxicity was measured using complete blood count, organ weight, body weight, water intake, food intake, blood profile for urea, creatinine, SGOT and SGPT (Using standard units of measurement as applicable for each parameter).

\section{Behavioral data analysis}

The locomotor activity and motor coordination activity were tested using actophotometer and rotarod respectively to evaluate alertness and muscle coordination (like balance and grip strength). Each experimental group consisted of 6 animals.

\section{a. Locomotor activity}

This study was performed to rule out the negative effect of SWRT on locomotor behavior of the animals if any. The horizontal locomotor activities of animals were recorded for a period of 5 minutes using 
actophotometer. The locomotor activity of the animals was observed twice before and 60 minutes after administration of the drug to evaluate the chronic toxicity of the plant extract.

\section{b. Motor coordination activity}

The effect of SWRT on motor coordination was studied using rotarod experimental system. The rotarod apparatus consists of a metal rod (3 $\mathrm{cm}$ diameter) coated with rubber, attached to a motor which rotates at a speed adjusted to 2 rotations per minute. The animals were trained to remain for three minutes on the rod rotating at a speed of $25 \mathrm{rpm}$. The fall off time from the rod was noted for each animal.

\section{c. Transfer latency (TL) and memory error test}

The effects of scopolamine on TL and memory impairments and its subsequent recovery by piracetam and SWRT were measured using (i) Elevated Plus Maze, (ii) Hebb Williams Maze and (iii) Radial Arm Maze.

(i). Elevated plus maze: The elevated plus-maze consists of two open arms $(16 \times 5 \mathrm{~cm})$ and two enclosed arms $(16 \times 5 \times 12 \mathrm{~cm})$. The maze was elevated to height of $25 \mathrm{~cm}$. Mice were placed individually at the end of an open arm facing away from central platform. The time taken by the animal to move from the open arm to either of closed arm (Transfer latency, TL) was recorded. If the animal did not enter into one of the closed arms within $90 \mathrm{sec}$, it was gently pushed into one of the two closed arms and the TL was assigned as $90 \mathrm{sec}$. The mice were allowed to explore the maze for another 2 minutes and then were returned to its home cage. Retention of this learned-task was examined after 24 hours from the first day trial.

(ii). Rectangular maze/ Hebb williams maze: The Hebb Williams maze is approximately $60 \mathrm{~cm} \mathrm{x} 60 \mathrm{~cm}$ with $10 \mathrm{~cm}$ thick walls made of wood. The Hebb Williams maze is divided into three chambers ( $\mathrm{A}, \mathrm{B}$ and $\mathrm{C}$ ). In chamber $\mathrm{A}$, the animal is placed at the beginning of the experiment, chamber $\mathrm{B}$, the reward is kept and the chamber $\mathrm{C}$, is partitioned with wooden slats into blind passages, leaving just one twisting corridor leading from the entry to the reward chamber. The presence of the animal in a particular chamber is indicated by glowing of light. The time taken by the animal to reach the reward chamber from the entry chamber through the maze is measured by the timer attached. The animals were trained for a period of 8 days and the animals with lower scores were used for experimental studies. Transfer latency is the time taken by the animal to reach the reward chamber (B) from the entry chamber (A). The transfer latency in the maze was measured after 45 min of the administration of Scopolamine and retention of memory after 24 hours.

(iii). Radial arm maze: The Radial Arm maze consists of eight arms extending in an octagonal shaped central hub (Lister, 1987). ${ }^{16}$ The platform is elevated $40 \mathrm{~cm}$ above the floor and small receptacles are placed at the end of teach arm that serves food pellets. The $1^{\text {st }}, 3^{\text {rd }}, 5^{\text {th }}$ and $7^{\text {th }}$ arms were baited and $2^{\text {nd }}, 4^{\text {th }}, 6^{\text {th }}$ and $8^{\text {th }}$ arms were unbaited. The baited and unbaited arms were fixed throughout the tests. Food deprived animals, maintained at $85 \%$ of its total diet, were trained for a period of 15 days. At the beginning of the experiment, the animals were placed on the central hub to test the animal for working memory and reference memory errors. The first entry into unbaited arms was scored as a reference memory error and re-entry into baited arms was scored as working memory error. The working memory and reference memory errors were measured after $45 \mathrm{~min}$ of administration of Scopolamine.

\section{In vivo antioxidant studies}

In vivo antioxidant activities of Catalase (Cat), Super Oxide dismutase SOD) and Reduced Glutathione (GSH) were conducted by the methods of Samuel et al (1950); McCord and Fridovich (1969) and Moron et al (1979), respectively. ${ }^{17-19}$

\section{Statistical analysis}

The statistical analysis was done using GraphPad Prism5. We also performed one way ANOVA followed by Dunnett's test and Tukeys multiple comparison test to find out the differences between control and treatment groups.

\section{RESULTS}

\section{Toxicity study of SWRT}

\section{Effect of Saraswatharishtam on acute toxicity in mice}

It was observed that there was no adverse effect on the behavioral parameters (Supplementary Table 1) like alertness, grooming, touch response, torch response, pain response, tremors and convulsions, gripping strength, pinna reflux, corneal reflux etc. Thus, it is understood that SWRT does not have any acute toxicity effect on the behavioral patterns of mice.

\section{Effect of SWRT on Chronic toxicity in mice}

Ayurveda medicine, SWRT does not shown any adverse effects when treated the mice with three different doses $(50,1000$ and $2000 \mathrm{mg} / \mathrm{kg}$ body weight). The results of the differential count of the blood has not affected with SWRT (Table 1). It was also observed that there were no significant changes in organ weight, food intake, water consumption and whole-body weight upon administration of SWRT (data not shown). The vital biochemical parameters in blood like, blood urea, creatinine, Serum Glutamic-Oxaloacetic Transaminase (SGOT) and Serum Glutamic-Pyruvic Transaminase (SGPT) does not reveal any noticeable changes when the animals were treated with all the three doses of SWRT (Table 2). To find out the effect of SWRT on locomotor activity we treated the animals with two different doses $(200 \mathrm{mg} /$ $\mathrm{kg}$ and $400 \mathrm{mg} / \mathrm{kg}$ ) in lieu of the doses we usually used. We did not find any noticeable changes in locomotor activity of the SWRT treated mice after 60 minutes of the drug administration when compared to the saline injected controls (Table 3). Also, we did not find any adverse effect on muscle coordination activity in SWRT treated animals and exhibited good balance, grip strength and muscle coordination as shown in (Table 4).

\section{Neuroprotective function of SWRT}

\section{Effect of SWRT on TL using Elevated Plus maze}

The elevated maze test was conducted to evaluate the preventive effect of SWRT on scopolamine induced learning and memory impaired mice. It was observed that scopolamine treated mice took longer time to locate the target on both the days studied (Figure 1a) so far due to the onset of amnesia. Both the doses of SWRT $(200,400 \mathrm{mg} / \mathrm{kg}$ ) significantly improved the learning and memory functions perturbed upon exposure to scopolamine. However, the standard drug piracitam improved the TL faster than SWRT. The TL was almost similar as control animals with time (day 9) when treated with higher dosage of SWRT $(400 \mathrm{mg} / \mathrm{kg})$. This specify that SWRT have the potentials to amliorate the scopolamine induced memory impairment in mice.

\section{Effect of SWRT on LT using rectangular maze}

The pretreatment of SWRT with both the doses, showed significant improvement of transfer latency performance which was negatively affected by scopolamine (Figure 1b). However, the performance at the dose of $400 \mathrm{mg} / \mathrm{kg}$ found to be better than the lower dose of SWRT (200 $\mathrm{mg} / \mathrm{kg}$ ) used for this experiment. It is interesting to note that piracetam has improved the performance levels well beyond the normal transfer latency on $8^{\text {th }}$ and $9^{\text {th }}$ day respectively. 
Table 1: Effect of SWRT on differential blood count of mice.

\begin{tabular}{|c|c|c|c|c|}
\hline Test & Control & $50 \mathrm{mg} / \mathrm{kg}$ & $1000 \mathrm{mg} / \mathrm{kg}$ & $2000 \mathrm{mg} / \mathrm{Kg}$ \\
\hline \multirow{2}{*}{ RBC } & \multirow{2}{*}{$6.86 \pm 0.15$} & $7.05 \pm 0.17$ & $6.83 \pm 0.51$ & $6.64 \pm 0.19$ \\
\hline & & (NS) & (NS) & (NS) \\
\hline \multirow{2}{*}{ WBC } & \multirow{2}{*}{$11.35 \pm 0.14$} & $11.22 \pm 0.82$ & $11.66 \pm 0.34$ & $11.02 \pm 0.77$ \\
\hline & & (NS) & (NS) & (NS) \\
\hline \multirow{2}{*}{ HB } & \multirow{2}{*}{$15.77 \pm 0.56$} & $16.07 \pm 0.85$ & $16.30 \pm 0.83$ & $16.08 \pm 0.77$ \\
\hline & & (NS) & (NS) & (NS) \\
\hline \multirow{2}{*}{ NEUTROPHILS } & \multirow{2}{*}{$19.33 \pm 0.98$} & $18.33 \pm 0.71$ & $18.50 \pm 0.76$ & $18.67 \pm 1.11$ \\
\hline & & (NS) & (NS) & (NS) \\
\hline \multirow{2}{*}{ LYMPHOCYTES } & \multirow{2}{*}{$73.00 \pm 2.80$} & $69.00 \pm 3.77$ & $69.17 \pm 2.42$ & $71.17 \pm 2.53$ \\
\hline & & (NS) & (NS) & (NS) \\
\hline \multirow{2}{*}{ MONOCYTES } & \multirow{2}{*}{$5.16 \pm 0.30$} & $5.66 \pm 0.61$ & $4.83 \pm 0.65$ & $5.50 \pm 0.56$ \\
\hline & & (NS) & (NS) & (NS) \\
\hline \multirow{2}{*}{ EOSINOPHILS } & \multirow{2}{*}{$2.33 \pm 0.66$} & $2.16 \pm 0.60$ & $2.16 \pm 0.60$ & $2.00 \pm 0.81$ \\
\hline & & (NS) & (NS) & (NS) \\
\hline
\end{tabular}

Table 2: Effect of SWRT on different blood parameters like urea, Creatinine, SGOT and SGPT in mouse model.

\begin{tabular}{|c|c|c|c|c|}
\hline Test & Control & $50 \mathrm{mg} / \mathrm{Kg}$ & $1000 \mathrm{mg} / \mathrm{Kg}$ & $2000 \mathrm{mg} / \mathrm{Kg}$ \\
\hline Urea & $23.03 \pm 0.75$ & $\begin{array}{l}22.49 \pm 0.80 \\
(\mathrm{NS})\end{array}$ & $\begin{array}{c}21.91 \pm 0.86 \\
(\mathrm{NS})\end{array}$ & $\begin{array}{c}23.48 \pm 0.90 \\
\text { (NS) }\end{array}$ \\
\hline Creatinine & $0.40 \pm 0.01$ & $\begin{array}{c}0.38 \pm 0.02 \\
(\mathrm{NS})\end{array}$ & $\begin{array}{c}0.39 \pm 0.01 \\
(\mathrm{NS})\end{array}$ & $\begin{array}{l}0.41 \pm 0.01 \\
(\mathrm{NS})\end{array}$ \\
\hline SOT & $109.0 \pm 3.18$ & $\begin{array}{c}113.2 \pm 4.41 \\
\text { (NS) }\end{array}$ & $\begin{array}{c}111.2 \pm 2.54 \\
(\mathrm{NS})\end{array}$ & $\begin{array}{c}112.8 \pm 3.10 \\
\text { (NS) }\end{array}$ \\
\hline SGPT & $40.00 \pm 1.59$ & $\begin{array}{c}41.00 \pm 1.18 \\
(\mathrm{NS})\end{array}$ & $\begin{array}{c}38.83 \pm 1.57 \\
(\mathrm{NS})\end{array}$ & $\begin{array}{c}40.33 \pm 1.92 \\
\text { (NS) }\end{array}$ \\
\hline
\end{tabular}

Table 3: Effect of SWRT on locomotor activity.

\begin{tabular}{|c|c|c|c|}
\hline \multirow{2}{*}{ Group } & \multirow{2}{*}{ Dose } & \multicolumn{2}{|c|}{ Locomotor Activity } \\
\hline & & Before & After $60 \mathrm{~min}$ \\
\hline Normal & Saline & $332.83 \pm 12.07$ & $349 \pm 11.17$ \\
\hline Test I & $200 \mathrm{mg} / \mathrm{kg}$ & $\begin{array}{c}355.66 \pm 13.16 \\
(\mathrm{NS})\end{array}$ & $\begin{array}{l}354 \pm 14.59 \\
(\mathrm{NS})\end{array}$ \\
\hline Test II & $400 \mathrm{mg} / \mathrm{kg}$ & $\begin{array}{c}348.66 \pm 12.47 \\
(\mathrm{NS})\end{array}$ & $\begin{array}{c}355 \pm 11.39 \\
(\mathrm{NS})\end{array}$ \\
\hline
\end{tabular}

Table 4: Effect of Saraswatharishtam on muscle relaxation.

\begin{tabular}{|c|c|c|c|}
\hline \multirow{2}{*}{ Group } & \multirow{2}{*}{ Dose } & \multicolumn{2}{|c|}{ Fall off time (sec) } \\
\hline & & Before & After $60 \mathrm{~min}$ \\
\hline Normal & Saline & $218.6 \pm 10.18 n$ & $219.6 \pm 7.31$ \\
\hline Test I & $200 \mathrm{mg} / \mathrm{kg}$ & $212 \pm 8.93$ & $228.66 \pm 14.28$ \\
\hline Test II & $400 \mathrm{mg} / \mathrm{kg}$ & $224.5 \pm 5.20$ & $225.5 \pm 11.18$ \\
\hline
\end{tabular}

\section{Effect of SWRT on Memory error}

The results of the working and reference memory errors test indicated that pretreatment with both the doses of SWRT significantly inverse the memory deficit induced by scopolamine (Figure 1c). Higher dose of SWRT even perform better and similar as piracetam.

\section{Effect of SWRT on antioxidant enzyme activity}

In vivo antioxidant studies indicated that SWRT has excellent in vivo antioxidant activity with respect to all the three enzymes namely, SOD, CAT and GSH (Figures 2a - c). We observe SWRT significantly restore the activity of these antioxidant enzymes and possibly could restrict generation of free radicals and subsequent neuronal damage due to its antioxidant potential.
Table 2 values are expressed as the mean \pm S.E.M. Statistical significances ( $\mathrm{p}$ values) calculated by one way ANOVA followed by Dunnett's Test $(P<0.05)$ to compare the differences between control VS different treatment groups. SWRT have no side effect on the differential counts of blood in mouse model (NS= Not significant).

Table 3 values are expressed as the mean \pm S.E.M Statistical significance ( $\mathrm{p}$ values) calculated by one way ANOVA followed by Dunnett's Test $(P<$ $0.05)$ to compare the differences between control VS different treatment groups. SWRT does not alter any values of the blood parameters studied (NS= Not significant).

Table 4 values are expressed as mean \pm S.E.M. Statistical significance ( $p$ values) was calculated by one way ANOVA followed by Tukey's multiple comparison test. Locomotor activity does not alter significantly (NS = Not Significant) after the treatment of SWRT. 


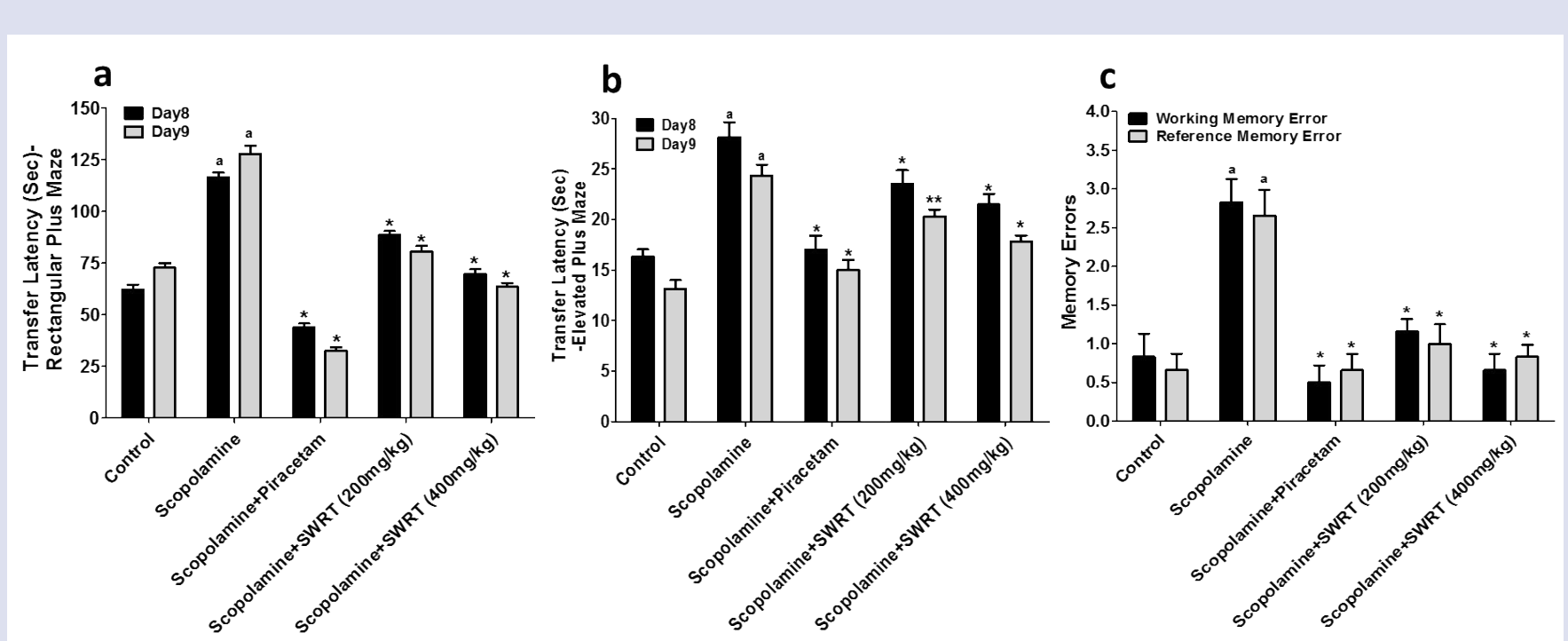

Figure 1: Saraswatarishtam ameliorates scopolamine induced defects in transfer latency (on elevated puls maze (a) and rectangular puls maze (b)) and memory errors (c). $\mathrm{a}=p<0.001$ (control VS Scopalamine); ${ }^{*}=p<0.001,{ }^{* *}=P<0.005$ (Scopalamine VS piracetam/ Saraswatatishtam). Each mean value is the average of at least six animals.

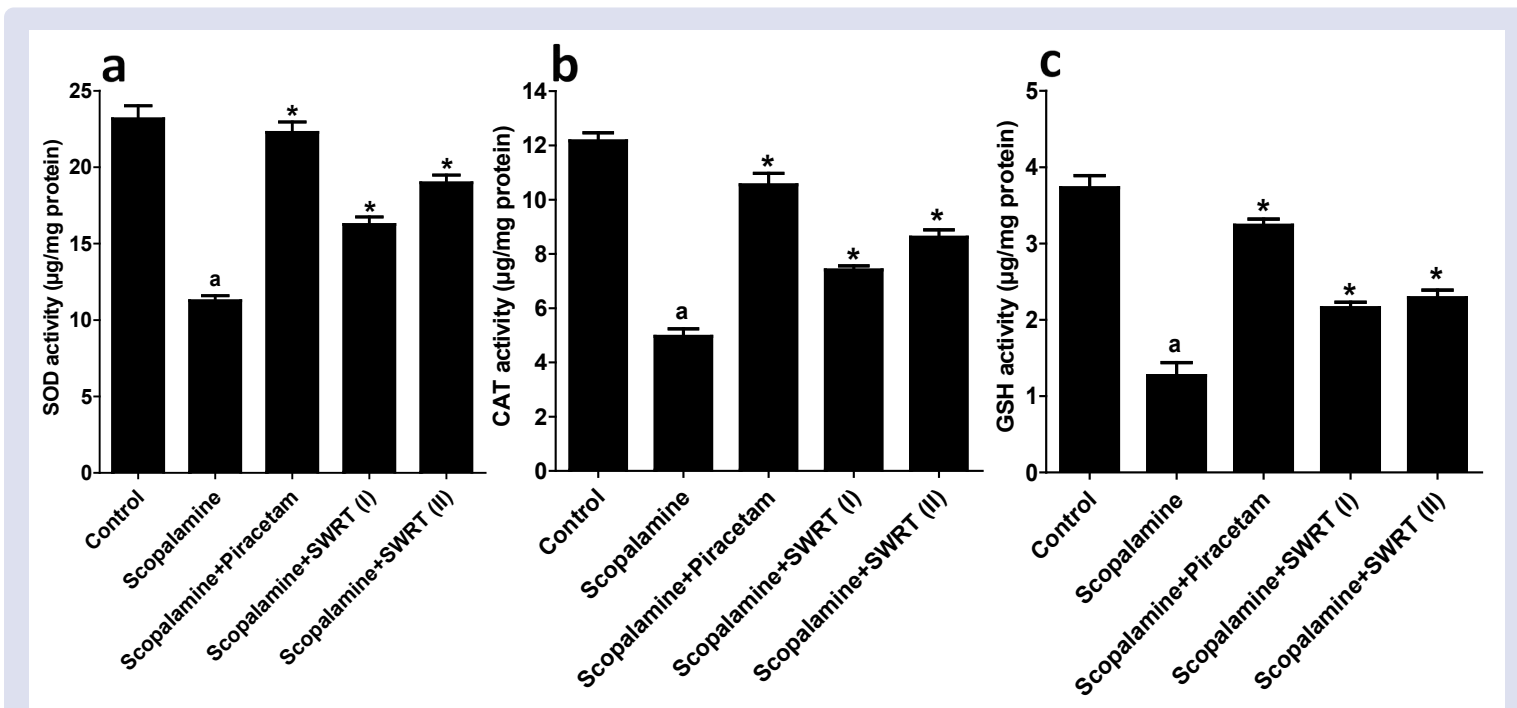

Figure 2: Saraswatarishtam rescues from scopolamine induced decline in antioxidant enzyme activity (a) SOD, (b) CAT and (c) GSH. $\mathrm{a}=p<0.001$ (control VS Scopalamine) $i^{*}=P<0.001$ (Scopalamine VS piracetam/Saraswatatishtam).

Figures 1 and 2 values are expressed as mean \pm S.E.M. Statistical significance ( $\mathrm{p}$ values) was calculated by one way ANOVA followed by Tukey's multiple comparison test. SWRT treatment has no adverse effect on muscle relaxation (NS = Not Significant).

Seventeen different types of normal behavioral and phenotypic attributes were studied after exposed the mice with SWRT and there were no toxic effect was recorded.

\section{DISCUSSION}

Indian traditional systems of medicines, Ayurveda and Sidhha are time tested and are in vogue since ages. Scientific validation however, is very important of this medication system. Ayurveda medicines are natural, easily affordable and easily available with less or no side effects. Scopolamine is a well-known synthetic drug which provokes learning and memory impairment while piracetam used as a pharmacological tool to evaluate the effects of cognitive enhancers on learning and memory deficits. ${ }^{20}$ In this study the effect of scopolamine on neurobehavioral dysfunction is assessed by observing the duration of transfer latency, working memory errors, reference memory errors using elevated plus maze, rectangular maze, and radial arm maze. We observed severe behavioral defects and memory deficits as side effects of scopolamine in the mouse model within 24 hours of the treatment. Present study indicated that pre feeding of SWRT at dosages of 200 and $400 \mathrm{mg} / \mathrm{kg}$ exhibited very satisfactory improvement by reducing its duration of transfer latency together with a refinement in memory deficit induced by scopolamine (working memory errors and reference memory errors). The study also proves that this drug has in-vivo antioxidant activities. Also, we did not find any toxic effect or side effects of SWRT when treated alone to test the toxicity, performing several pathophysiological and behavioral tests. The information concerning the validations of such plant medicine on neuro-protective function of SWRT are not much available. Recently two major biomolecules, namely eugenol and serine were found to be predominantly present 
in SWRT. ${ }^{21}$ Interestingly these two bioactive molecules are reported as neuro-protective and neuroplastic molecules (FAO Report, 1982 Wang et al, 2010 $\left.{ }^{23}\right) .^{22,23}$ Eugenol exerts a neuro-protective potential against brain induced toxicity as demonstrated by reducing neuronal cell damage of cerebral cortex and preservation of small pyramidal cells of the hippocampus. ${ }^{24}$ In addition, direct neurotrophic effect of eugenol was also previously reported by inducing brain derived neurotrophic factor (BDNF) gene expression in the hippocampus. ${ }^{25}$ This compound also have ability to inhibit monoamine oxidase A (MAO-A) and help to restore monoamines in the brain.

Piracetam comes under smart drugs used for neuro-protection on experimental animals since last three decades. This plays a critical role enhancing acetylcholine function through muscarinic cholinergic receptors and these receptors play a vital role in memory and learning. Piracetam exerts its action by enhancing cell membrane permeability and increase oxygen consumption by elevating the adenylate kinase activity in brain. ${ }^{26,27}$ This drug is mainly used to treat a wide range of neurological abnormalities like seizures, epilepsy, myoclonus, dementia, myoclonus or Alzhemier's disease, multi infarct dementias, senile dementia, alcoholism, Parkinson's diseases etc. It has reported that piracetam produces neuro plasticity and it enhances memory and learning process thereby preventing lesions and ischemic damages. It also has anti-convulsion activity and enhances micro circulation and can be used as therapy in cerebral ischemia. Piracetam being a synthetic chemical have some side effects with over doses. Thus, we conclude from our findings that SWRT could be used as an alternative medicine to treat learning and memory deficits, as this natural plant product have no side effects. We also suggest, SWRT is a promising medicine in prophylaxis and treatment of neuropsychiatric and neurodegenerative diseases. Although there are reports on the anxiolytic and antidepressant activities of SWRT, there is a dearth of information regarding the effect of Saraswatharishtam on memory function and therefore the present study encompasses its role on various neurobehavioral parameters in animal model.

The nervous system is a complex cellular network composed of as many as 10 billion neurons and 60 trillion synapses that mediate interneuronal communication. Each neuron can be regarded as a component in a complex system of highly specialized, distinct neural circuits. ${ }^{27}$ Every aspect of behavior, from primitive reflexes to abstract thinking and emotion, relies on the precision of the computational processes performed by these circuits, which in turn is critically dependent on healthy excitatory and inhibitory systems. ${ }^{29}$ Thus, excitatory to inhibitory cortical activity and its imbalance could explain the etiology of cognitive defect in various neurological diseases like autism, schizophrenia etc. It is noteworthy to mention that like piracetam, SWRT may also have nootropic properties indicating its ability to interact with target receptors in the brain which need further investigations. Both the drugs, piracetam and SWRT, have the capacity to ameliorate memory errors, cognitive enhancement and anti-depressive and anxiolytic effects. We observed that piracetam extremely reduces the latency period (in rectangular maze and working memory errors) compared to normal saline fed animals showing over cortical excitability of the brain function. This over excitability could lead to physio-pathological fatigue to the brain. However, SWRT reverses the scopolamine induced temporary defects to normal level as reflected in the values in rectangular maze, radial arm maze experiments. Thus, SWRT could be safe to use for neurological dysfunctions including memory loss without any after effect or side effects in the animals.

Formation of memory is a very complex process involving multiple neuronal pathways and neurotransmitter. The cholinergic neuronal system is known to play an important role in memory in human and animals. ${ }^{29}$ Scopolamine interferes with memory function and causes memory impairment of spatial memory and SWRT manifest improvement in working and reference memory in radial arm maze task. Working memory is important for reasoning and guidance of decision making and behavior. It temporarily holds the information available for processing. Working memory and reference memory are the two variables that report the physiological status of the brain and this suggest the increase in the behavioral parameters which again proves that SWRT has the ability to sustain memory and promote learning and memory performance. ${ }^{30}$

Radial arm maze performance is an appetitive motivation task that is useful to assess the spatial reference as well as spatial working memory performance. ${ }^{31,32}$ Results of this study showed that pretreatment (oral administration) of SWRT significantly prevented the higher reference memory and working memory errors. These finding furthermore suggests that SWRT ameliorates the memory impairment in mouse model.

Reactive Oxygen Species (ROS) are generated continuously in nervous system during normal metabolism and neuronal activity. The nervous system is particularly vulnerable to deleterious effects of ROS since the brain has high consumption of $\mathrm{O}_{2}$, polyunsaturated fatty acids and high content of free ions. The oxidation of monoamines and catecholamines can lead to ROS production in the brain. During this oxidative process, the level of glutathione (GSH), catalase and SOD enzymes level used to be decreased in the brain. In this study it is evident that SWRT is able to scavenge ROS by its anti-oxidative activities and thus regulate the endogenous antioxidant defense mechanism. Antioxidant property is a basic character of the traditional herbal preparations and has neuroprotective and or neuroregerative roles by reversing or reducing cellular damage and retarding the progression of neuronal loss. ${ }^{33,34}$ The in vivo antioxidants study augurs well with similar report on the in vitro antioxidant role of SWRT was reported. ${ }^{36}$

Thus, it is evident that SWRT restores the negative effect of scopolamine slowly but steadily when compared to that of commonly used drug piracetam. It could be stated that SWRT, being a slow acting medicine could help to minimize the adverse effect of other major drugs like tricyclic antidepressants (TCAs), monoamine oxidase inhibitors (MAOIs) and the newer agents like selective serotonin reuptake inhibitors (SSRIs) and selective norepinephrine reuptake inhibitors (SNRIs) etc. The superiority to use of the Ayurvedic medicines is their ability in restoration of health due to their less side effects as compared to synthetic medicines. Taken together, we suggest that SWRT could be considered as a potent neuro-protective drug with no adverse effect on health.

\section{CONCLUSIONS}

In vivo antioxidant activity results strongly indicate the antioxidant properties of SWRT which augurs well with medicinal activities especially reinstating memory and learning function. The study justifies the potential of SWRT to ameliorate memory impairment with non-toxicological property in scopolamine induced rat model. Pharmacological and translational research is needed to explore the molecular mechanisms behind the neuro-protective functions of SWRT. It is suggested that the coupling of Ayurvedic formulations, after due confirmation, with molecular medicinal regimens to have better results in managing neuro-degenarative and neuropsychiatric diseases.

\section{ACKNOWLEDGEMENTS}

The authors acknowledge all concerned who have helped directly or indirectly in bringing about this work.

\section{ABBREVIATION}

SGOT: Serum Glutamic Oxaloacetic Transaminase; SGPT: Serum Glutamic Pyruvvate Transaminase; TCA: Tricyclic Ant depressors; 
MAOI: Mono Aminase Oxidase Inhibitor; SSRI: Selective Serotonin Reuptake Inhibitor; SNRI: Selective Neuro-epinephrine Receptor Inhibitor; SWRT: Saraswatharistham; TL: Transfer Latency; BHT: Butylated hydroxy toluene; ROS: Reactive Oxygen Species; GSH: Reduced Glutathione; SOD: Superoxide Dismutase; BDNF: Brain Derived Neurotrophic Factors.

\section{DECLARATIONS}

1. Ethics approval and consent to participate. All experimental procedure was approved by IAEC (Institution of Animal Ethical Committee) of KMCH governed by CPCSEA, Government of India. Proposal number: 685/PO/02/a/CPCSEA/ 2015-2016.

2. Consent for publication. Since no human experiments were undertaken, approval of consent was not applicable. All the authors have given their consent for publication of this article.

3. Availability of data and material. We have not used any genetic data base or sequence data base, the need for indicating such does not arise. All the necessary data and materials are included in the article which can be used in public domain and are attached as supplementary files.

4. Competing interests. "The authors declare that they have no competing interests"

5. Funding. The project is Self-stipendiary and no external funding was availed.

6. Authors' contributions: JP: Concept and designing, Data acquisition, Provision of study materials. KP: analysis and interpretation of data, article drafting, final approval of article, AC: Concept and designing, analysis and interpretation of data, article drafting, statistical expertise, MRKR: Concept and designing, analysis and interpretation of data, article drafting, Collection and assembling data, final approval of article, VSKS: Concept and designing, analysis and interpretation of data, article drafting, final approval of article, TKB: Concept and designing, analysis and interpretation of data, article drafting, final approval of article, SD: Concept and designing, analysis and interpretation of data, article drafting.

7. Authors' Information. Jai Prabhu ${ }^{1}$, Research Scholar, Sree Balaji Medical College and Hospital, Chennai. jaiprabhusp@gmail. com.; K Prabhu², Associate Professor, Dept of Anatomy, Sree Balaji Medical College and Hospital. prabanu75@gmail.com. 9841171185; Anathbandhu Chaudhuri ${ }^{3}$, Assistant Professor, Department of Biological Sciences, University of Alabama, Tuscaloosa, Alabama, 35401, USA, chaudhur@ua.edu.; Mudiganti Ram Krishna Rao ${ }^{4^{*}}$ Professor, Department of Industrial Biotechnology, Bharath Institute of Higher Education and Research, Chennai.mrkrao1455@gmail.com. 9894994567; V S Kalai Selvi ${ }^{5}$, Professor, Department of Biochemistry, Sree Balaji Medical College and Hospital, Chennai. doc.kalaiselvi@ gmail.com. 9884218580; T. K. Balaji6, Professor, Dept. of Anatomy, Chettinad Health City, Chennai 603103; balajitk@yahoo.com; Sruthi Dinakar ${ }^{7}$, Ayurvedic Physician, Kottakkal Arya Vaidhya Sala, Chennai. sruthidinakar@gmail.com.9791053873.

\section{REFERENCES}

1. Chapman DP, Williams SM, Strine TW, Anda RF, Moore MG. Dementia and its implications in public health. Prev Chronic Dis. 2006;3:A-34.

2. Peacock CS, Moammond-Collins K, Forbes DA. The journey with dementia from the perspective of bereaved family caregivers: a qualitative descriptive study. BMC Nurs. 2014;13:42

3. Parekar RR, Jadhav KS, Marathe PA, Rege NN. Effect of Saraswatarishta in animal models of behavior despair. J Ayurveda Integr Med. 2014;5:141-7.

4. Gupta K, Ashok BK, Ravishankar B, Thakar AB. Anti-anxiety and anti-depressant activities of Sarasvata choorna in experimental animals. Ayu. 2011;32:590-3.

5. van der Staay FJ, PC Bouger. Effects of the cholinesterase inhibitors donepezil and metrifonate on scopolamine induced impairment in the spatial cone field orientation task in rats. Behav Brain Res. 2005;156:1-10.
6. Harandi S, Golchin L, Ansari M, Maradi A, Shabani M, Sheibani V. Antiamensic effects of walnut consumption on Scopolamine induced memory impairments in rats. Basic Clin Neurosci. 2015;6(2):91-9.

7. Appenroth D, Decker M, Trankle C, Mohr K, Lehmann J, FleckC. In vivo investigations on the cholinesterase - inhibiting effects of tricyclic quinazolinimines: scopolamine induced cognitive impairments in rats are attenuated at low dosage and reinforced at higher dosage. Pflugers Arch. 2008;455:895-901.

8. Bajo R, Pusil S, Lopez ME, Canuet L, Pereda E, Maestu F, Pekkonen E Scopolamine effects on functional brain connectivity: A pharmacological model of Alzheimer's disease. Scientific Reports. 2015:1-6.

9. Jawaid T, Jahan S, Kamal M. A comparative study of neuroprotective effect of angiotensin converting enzyme inhibitors against scopolamine-induced memory impairments in rats. J Adv Pharm Technol Res. 2015;6:130-5.

10. Mesripour A, Mamoud R, Bahareh B. Effects of Anethum graveolens essence on Scopolamine induced memory impairment in mice. Res Pharm Sci. 2016;11:145-51.

11. Uebelhack R, Vohs K, Zytowski M, Schewe HJ, Koch C, Konertz W. Effect of piracetam on cognitive performance in patients undergoing bypass surgery. Pharmacopsychiatry. 2003;36:89-93.

12. Alkuraishy $\mathrm{H}$, Algareeb A, Albuhadilly A, Almgoter B. Modulation Effects of Piracetam and Ginkgo Biloba on the Cognitive and Working Memory Functions: Psychometric Study. J Neurol Neurophysiol. 2014;5:1-6.

13. Zaki FH, Abd-El-FattahMA A, Attia AS. Naringenin protects against scopolamineinduced dementia in rats. Bulletin of faculty of Pharmacy, Cairo University, 2015;52:15-25

14. Pahaye DB, Bum EN, Taiwe GS, Ngoupaye GT, Sidiki N, Moto FCO, et al. Neuroprotective and antiamnesic effects of Mitragyna inermis Willd (Rubiaceae) on Scopolamine induced memory impairment in Mice. 2017;11.

15. Rao MRK, Vijayalakshmi N. Preliminary phytochemical and GC MS analysis of different extracts of Sphaeranthus indicus leaves. Indo American $\mathrm{J}$ of Pharmaceutical Sciences. 2018;5:1511-20.

16. Lister RG. The use of a Plus Maze to measure anxiety in the mouse Psychopharmacology. 1987;92:180-5.

17. Samuel A, Goldblith, Bernard E. Proctor. Photometric determination of catalase activity. J Biol Chem. 1950;187:705-9.

18. McCord JM, Fridovich I. Superoxide dismutase. An enzymic function for erythrocuprein (hemocuprein). J Biol Chem. 1969;244:6049-55.

19. Moron MS, JW Depierre, B Mannervik. Levels of glutathione, glutathione reductase and glutathione $S$-transferase activities in rat lung and liver. Biochimica et Biophyscica Acta (BBA). 1979;582:67-78.

20. Leuner K, Kurz C, Guidetti G, Orgogozo J, Muller WE. Improved mitochondria function in brain aging and Alzeimer disease- the new mechanism of action of the old metabolic enhancer Piracetam. Front Neurosci. 2010;4:44.

21. Ravi A, Jai Prabhu SP, Mudiganti Ram Krishna Rao, Prabhu K, Kalaiselvi KVS, Saranya Y. Identification of Active Biomolecules in Saraswatarishtam (An Ayurvedic Preparation) by GC-MS Analysis. Int J Pharm Sci Rev Res. 2015;33:58-62.

22. FAO: Evaluation of certain food additives and contaminants. Technical Report Series No. 20. Geneva. Switzerland, FAOMHO Expert Committee on Food Additives. 1982.

23. Wang GH, Jiang ZL, Chen ZQ, Li X, Peng LL. Neuroprotective effect of L-serine against temporary cerebral ischemia in rats. J Neurosci Res. 2010;88:2035-45.

24. Said MM, Rado MMA. Neuroprotective effects of eugenol against aluminium induced toxicity in rat brain. Archives of Industrial Hygiene and Toxicology. 2017;68:27-37.

25. Irie Y, Keung WM. Rhizoma acori graminei and its active principles protect PC 12 cells from the toxic effect of amyloid-b peptide. Brain Res. 2003;963:282-28.

26. Suliman NA., Taib CNM, Moklas MAM, Adenen MI, Baharuldin MTH, Basir R. Establishing natural nootropics: recent molecular enhancement influenced by Natural Nootropics. Evid Based Comp Altern Med. 2016;2016.

27. Badawy RA., LoetscherT, Macdonell RA, Brodtmann A. Cortical excitability and neurology: insights into the pathophysiology. Funct Neurol. 2013;27:131-45.

28. Robinson DA. Implications of neural networks for how we think about brain function. Behav Brain Sci. 1992;13:644-55.

29. Picciotto MR, Higley MJ, Mineur YS. Acetylcholine as a neuromodulator cholinergic signaling shapes nervous system function and behavior. Neuron 2012;76:116-29.

30. Titus ADJ, Rao SBS, Harsha HN, Ramkumar K, Srikumar BN, S. Singh SB, Chatterjee S. Hypobaric hypoxia- induced dendritics of Hippocampus neurone associated with cognitive impairment in adult rats. Neuroscience. 2007;145:265-78.

31. McGurk SR, Levin ED, Butcher LL. Impairment of radial arm maze in rats following lesions involving the cholinergic medial pathways: reversal by arecoline and differential effects of muscarinic and nicotinic antagonists. Neuroscience. 1991;44:137-47. 
32. Bowman RE., Zrull MC, Luine VN. Chronic restraint stress enhances radial arm maze performance in female rats. Brain Res. 2001;904:279-89.

33. Kolominsky-Rabas PL, Sarti C, Heuschmann PU, Graf C, Siemonsen S, Neundoerfer B, et al. A prospective community based study of stroke in Germany. The Erlangen stroke project (Espro): incidence and case fatality at 1 , 3, and 12 months. Stroke. 1998;29:2501-6.
34. Commenges D, Scotet V, Renaud S, Jacqmin -Gadda H, Barberger Gateau P, Dartigues JF. Intake of flavonoids and risk of dementia. Eur J Epidemiol. 2000;16;357-63.

35. Prabhu J, Prabhu K, Rao MRK, Kalaiselvi VS, Krishna V, Ramesh A. The in vitro antioxidant studies of one Ayurvedic medicine "Sarawatharihtam." IJPSRR 2017:44:235-9.

\section{GRAPHICAL ABSTRACT}
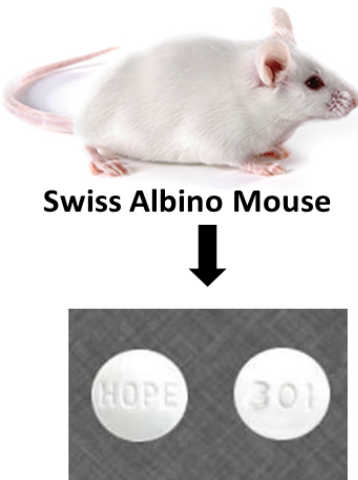

Scopolamine

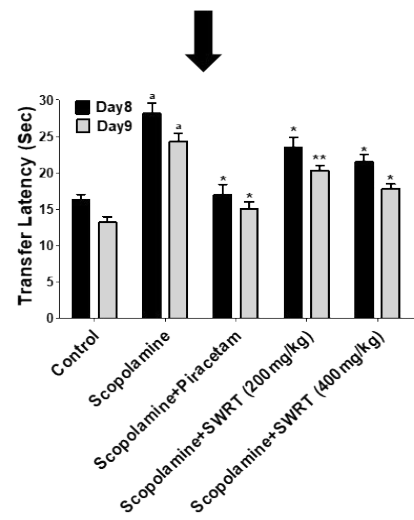

Motor Coordination

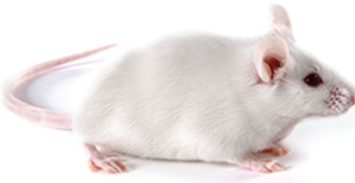

Swiss Albino Mouse

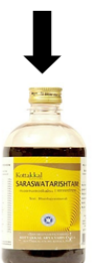

Saraswatharishtam

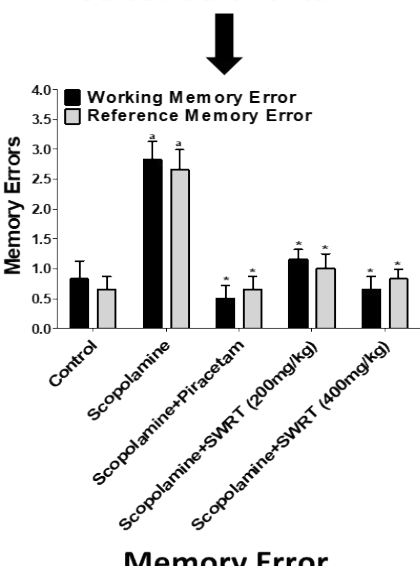

Memory Error

\section{SUMMARY}

Sarasawatharistham (mixture of 18 different types of Indigenous plants), an Ayurvedic preparation found to be a potential neuroprotective tonic when treated to the scopolamine induced memory impaired mice model without showing any acute or chronic side effects. The positive effects of such plant derived medicine on memory loss are very much comparable with the synthetic neuro-protective medicine piracetam, which have several side effects on human health. We suggest that SWRT could be a safe and easily available Ayurvedic medicine to treat neurological dysfunctions.

Cite this article: Prabhu J, Prabhu K, Chaudhuri A, Rao MRK, Selvi VSK, Balaji TK, et al. Neuro-protective Effect of Ayurveda Formulation, Saraswatharishtam, on Scopolamine Induced Memory Impairment in Animal Model. Pharmacog J. 2020;12(1):06-13. 